\title{
Tooth loss in the population of south-eastern Poland
}

\author{
Leszek Szalewski', Joanna Rosiak², Beata Kubić-Filiks², Elżbieta Pietryka-Michałowska³, \\ Jolanta Szymańska² \\ ${ }^{1}$ Department of Dental Prosthetics, Medical University of Lublin, Poland \\ ${ }^{2}$ Chair and Department of Paedodontics, Medical University of Lublin, Poland \\ ${ }^{3}$ Department of Mathematics and Medical Biostatistics, Medical University of Lublin, Poland
}

Szalewski L, Rosiak J, Kubić-Filiks B, Pietryka-Michałowska E, Szymańska J. Tooth loss in the population of south-eastern Poland. J Pre-Clin Clin Res. 2016; 10(2): 105-109. doi: 10.5604/18982395.1227566

\begin{abstract}
Objectives. The aim of the study was to analyze the relationship between selected socio-demographic factors and tooth loss in patients using removable dentures.

Materials and method. The study comprised 321 individuals, all of whom were residents of the Lublin province in southeastern Poland. The study investigated the influence of socio-demographic factors, such as gender, age and education on the severity of tooth loss. To analyze the structure of tooth loss, the classifications by Galasińska-Lansberger and by Eichner were used. The results were analyzed statistically.

Results. Edentulous gaps and lateral edentulism in the maxilla were significantly more frequent in women, while mixed tooth loss was more frequent in men, while the percentages of men and women with maxillary edentulism were similar. There were no statistically significant gender-specific differences concerning mandibular edentulism. The number of individuals who reported total tooth loss in both the maxilla and the mandible increased with age, the differences being statistically significant. Individuals with primary education only were significantly more likely to report maxillary edentulism, while a high percentage of those with secondary or higher education reported edentulous gaps in the maxilla. There was no statistically significant relationship between education and the type of tooth loss in the mandible.

Conclusions. There is a strong relationship between age and education level on the one hand, and the severity of tooth loss on the other. However, gender exerts no significant influence on tooth loss, which was confirmed using 2 classifications of edentulism.
\end{abstract}

\section{Key words}

edentulism, socio-demographic factors, Polish population

\section{INTRODUCTION}

In 2010, edentulous people constituted some $2.3 \%$ of the global population (158 million people). Determining the highest possible number of factors that might affect this appears important. Researching the epidemiology of tooth loss would make it easier to prevent and cure edentulism [1], allowing individuals to keep the masticatory system functioning and the teeth healthy. There is a strong relationship between low socio-economic status and poor oral health. Such a tendency is present both in rich and developing nations [2]. In 2006, the World Health Organization (WHO) found the following factors to have impact on oral health: gender, age, work environment, education level, medical care availability, food and drinking and water quality. Taking action by the government toward implementing health-oriented policies, both on the local and national level, and promoting various social actions focusing on healthy lifestyle, including oral health, might positively affect oral health indexes. The WHO have paid special attention to improving the health of people living in East and Central Europe. They have done so by recognizing the health needs by various societies and tackling negative social trends [3].

Address for correspondence: Jolanta Szymańska, Chair and Department of Paedodontics, Medical University of Lublin, Poland

E-mail: szymanska.lublin@gmail.com

Received: 20 July 2016; accepted: 29 September 2016
The number of edentulous individuals has decreased over the past years and so has the demand for complete dentures; however, the number of people using partial dentures has increased. Despite the overall trend, there are still differences in terms of edentulism prevalence, both on the national and regional level [4]. Research studies conducted in Poland between 1998 - 2009 paint a totally different picture. At that time, the number of edentulous individuals aged 3544 had more than doubled. The number of individuals of both genders keeping the masticatory system functional has decreased. At the same time, the number of people with natural teeth has slightly increased over the decade [5].

Numerous studies investigating the relationship between teeth loss and socio-economic status have been conducted worldwide, although there are some important discrepancies between these findings [6]. Some consequences of teeth loss include deterioration of masticatory functions, neuromuscular disorders, as well as disrupted occlusal relationships, which may hugely deteriorate the quality of life [7]. There are also some aesthetic concerns related to teeth loss, which may affect the social acceptance of individual people [8].

\section{OBJECTIVE}

The presented study investigated the relationship between selected socio-demographic features and teeth loss in residents using removable dentures in the Lublin Region. 


\section{MATERIALS AND METHOD}

321 individuals using removable dentures, all residents of Lublin Region in south-eastern Poland, were chosen at random. The authors of the study assessed the influence of the following factors: gender, age, education over tooth loss. The subjects were divided into 3 age groups: up to 50 years of age, 51-70 years of age, and over 70 years of age. The subjects were also divided according to their educational level: basic, professional, as well as middle and higher education. A classification by the Galasińska-Landsberger and Eichner Index were used. The former distinguishes between 5 classes of teeth loss. Class 1 - damage of either one tooth or a group of teeth located close to the dental arch, class 2 - interdental loss, class 3 - edentulous areas (either uni- or bilateral) located posterior to the remaining natural teeth, class $4-$ mixed teeth loss (missing anteriors and posteriors), and class 5 - edentulism [9]. Eichner divided occlusal contact between natural teeth into the following classes: A, B, C, further divided into smaller groups. Class A - a maximum of four supporting zones, out of which different groups are distinguished: A1 (a dental arch with 4 support zones without any lacking teeth), A2 (A dental arch with 4 support zones with tooth loss on one side of the jaw) and A3 (a dental arch with 4 support zones, with tooth loss on both the lower and upper mandibles). Class B is defined as having 1-3 supporting zones, or tooth contact in the frontal area only: B1 - a denture with 3 support zones, B2 - a denture with 2 support zones, B3 - a denture with 1 support zone, and B4 - a denture without any support zone and with contact occlusion only at the anterior teeth. Class $\mathrm{C}$ has no supporting zones: $\mathrm{C} 1 \mathrm{-a}$ denture without any support zones with teeth remaining on the lower and upper mandible, C2 - a denture without any support zone with one edentulous jaw, and C3 - edentulism in both maxilla and mandible [9]. The results were analyzed statistically. The data was analyzed using Statistica 10.0 software (StatSoft, Poland).

\section{RESULTS}

Galasińska-Landsberger classification - Maxilla. Genderspecific analysis of maxillary edentulism showed that women statistically more frequently experienced interdental losses (class II) or edentulous space (class III) in the maxilla, while in case of men, these were mainly mixed losses (class IV). The percentage of men and women suffering from maxillary edentulism was similar (Fig. 1).

Taking various age groups into consideration, the reported differences were deemed statistically significant $\left(\mathrm{Chi}^{2}=20.29\right.$; $\mathrm{df}=6 ; \mathrm{p}=0.002$ ) (Fig. 2). The number of edentulous individuals increased with age.

It was noted that patients' educational level had some statistically significant influence over teeth losses in the jaw $\left(\mathrm{Chi}^{2}=14.72 ; \mathrm{df}=6, \mathrm{p}=0.023\right)$ (Fig. 3).

Mandible. The presented study paid attention to mandibular edentulism, using the classification by GalasińskaLandsberger. It was reported that class 2 occurred in 13 female patients, class 3 in 66 patients (30.14\%), class 4 in 91 patients $(41.55 \%)$, and class 5 in 49 patients (22.37\%). In the case of male patients, class 2 was reported in 10 patients (9.80\%), class 3 in $34(33.33 \%)$, class 4 in 42 (41.18\%), and

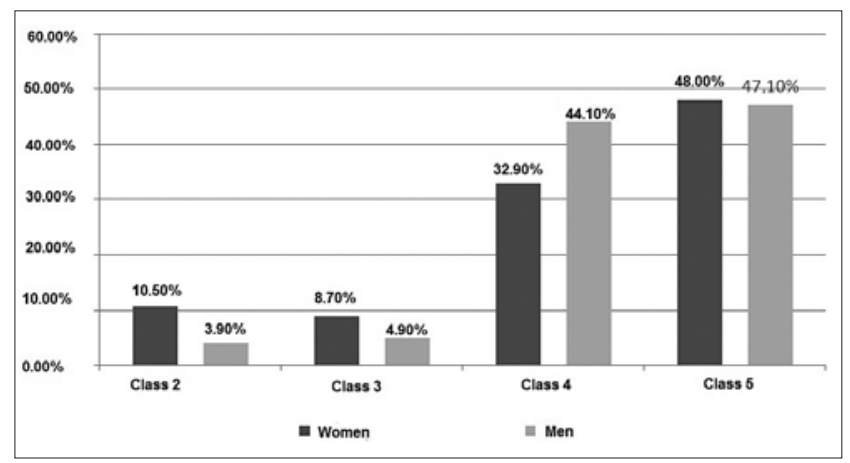

Figure 1. Maxillary edentulism by gender (using the classification by GalasińskaLandsberger)

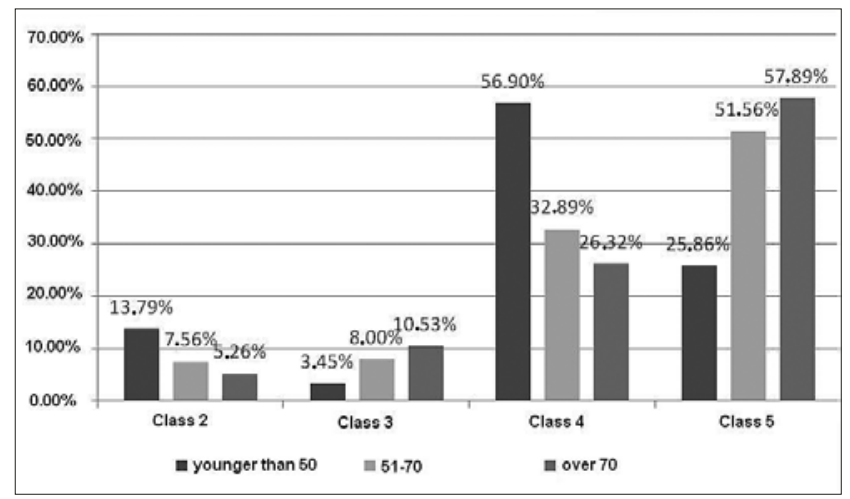

Figure 2. Maxillary edentulism by age groups (using the classification by Galasińska-Landsberger)

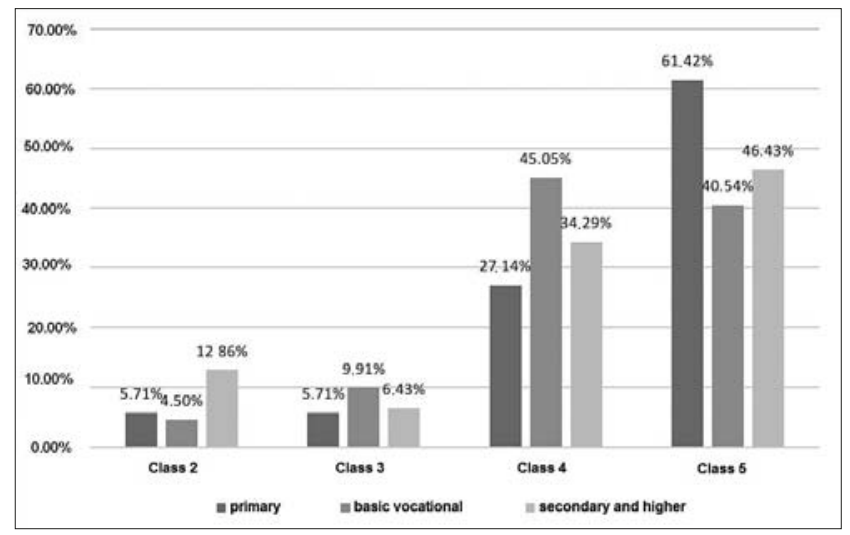

Figure 3. Maxillary edentulism by educational level (using the classification by Galasińska-Landsberger)

class 5 in 16 patients (15.69\%). There were no statistically significant gender differences in this regard $\left(\mathrm{Chi}^{2}=3.22 ; \mathrm{df}=3\right.$; $\mathrm{p}=0.359$ ).

Taking various age groups into consideration, the reported differences were deemed statistically significant $\left(\mathrm{Chi}^{2}=21.88\right.$; $\mathrm{df}=6 ; \mathrm{p}=0.001$ ) (Fig. 4). There were no statistically significant differences between subjects of different educational levels $\left(\mathrm{Chi}^{2}=8.55 ; \mathrm{df}=6 ; \mathrm{p}=0.20\right)$. Despite that, most subjects suffering from class 3 edentulism (edentulous areas located posterior to the remaining natural teeth) were those who had basic vocational education, while in the case of edentulous subjects (class 5), most had primary education only (Fig. 5).

Eichner Index. In the case of distribution of missing teeth in the study group according to the Eichner classification, the 


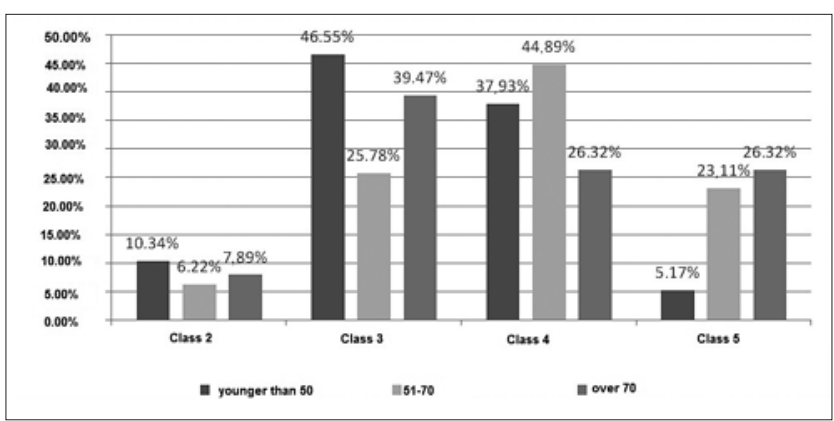

Figure 4. Mandibular edentulism by age (using the classification by GalasińskaLandsberger)

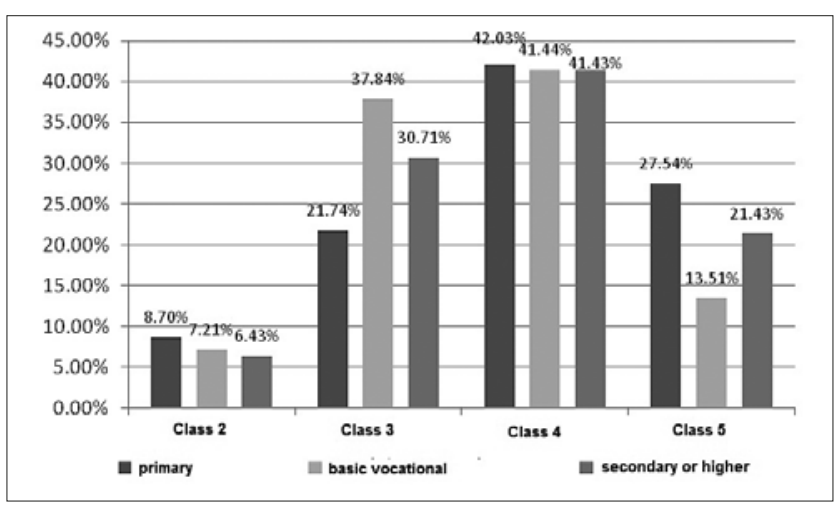

Figure 5. Mandibular edentulism by educational level (using the classification by Galasińska-Landsberger)

findings were as follows: class B1 - 3 patients (0.93\%), class B2 - 19 patients (5.92\%), class B3 - 48 patients (14.95\%), class B4 - 51 patients $(15.89 \%)$, class C1 - 39 patients $(12.15 \%)$, class C2 - 104 (32.40\%), and class C3 - 57 patients (17.76\%).

The classification by Eichner was used to assess the differences in teeth loss between men and women and revealed no statistically significant differences $\left(\mathrm{Chi}^{2}=8.06\right.$; $\mathrm{df}=6 ; \mathrm{p}=0.17$ ).

Due to an insufficient number of subject fitting particular categories, they were divided into 2 age groups. The first comprised subjects aged up to 50, while the other consisted of patients over the age of 50. It appeared that teeth losses (assessed using the Eichner Index) were statistically related to patients' age $\left(\mathrm{Chi}^{2}=29.69 ; \mathrm{df}=6 ; \mathrm{p}=0.01\right)$. One-third of the subjects in the older age group were reported with Eichner Class C2 - a denture without any support zone with one edentulous jaw, and another one-fifth were reported with both jaws edentulous (Class C3).

There is a statistically significant relationship between education level and teeth loss. Apparently, there are some differences between patients with different education levels (Chi2 $=25.53 ; \mathrm{df}=12 ; \mathrm{p}=0.012$ ). Over a quarter of subjects with primary education had no teeth in the mandible and the maxilla (C3), while about one-third had a denture without any support zone, with one edentulous jaw (C2 group).

\section{DISCUSSION}

The authors' own research has shown that the number of edentulous people increases along with age. This tendency appears in both the upper and lower dental arch, and complies with the results of various studies conducted in
Europe, Africa, Asia and South America showing that the prevalence of the condition has increased [10-15], and that the overall number of teeth has decreased [1,16-19]. Also, one study has shown that the prevalence of the disease increased with age, and partial tooth loss was more likely to occur in individuals over 60 [1].

The prevalence of maxillary edentulism was as follows: $51.56 \%$ of the patients aged $51-70$ and $57.89 \%$ of the patients older than 70 were reported with the condition. Furthermore, $26.32 \%$ of subjects over 70 were edentulous in the maxilla. Of all subjects, Class C3 of the Eichner Index (both jaws are edentulous) was reported in $17.75 \%$ of cases, while in the over 50 group, it happened to $20.53 \%$. For the sake of comparison, a study by Peltzer et al., conducted in 6 countries located on 4 continents revealed that $11.7 \%$ of subjects over 50 years of age were edentulous. The highest number of edentulous individuals was reported in Mexico, while the lowest in Ghana. It needs emphasizing that there were slightly more women among the subjects [15].

The findings by the authors of the present study differ from the results obtained by Ozkan et al., who found that the prevalence of edentulism in patients aged $65-90$ was $60 \%$. Yet, there is a certain similarity between the 2 studies concerning the share of edentulous individuals by gender. A study by Turkish authors revealed that females were more likely to be edentulous (61\%) than men (39\%) [20]. The authors' own study revealed similar findings, both in the maxilla and mandible. Women were more frequently reported to have total edentulism (Class V according to Galasińska-Landsberger's classification). It needs emphasizing that these differences were not statistically significant. A common analysis for both arches revealed some significant differences - 73.68\% of women were edentulous (Class 3 according to the Eichner Index). A similar tendency was revealed in Brazilian studies where $70.5 \%$ of edentulous people were women [7]. Basnyat et al. found no statistically significant gender differences when researching edentulism [12].

A study by Radovic et al. revealed that some $28.8 \%$ of the subjects aged 65-74 were edentulous and most of them were female [21]. A study conducted in northern Italy revealed that $43.8 \%$ of subjects over 65 were edentulous, $31.8 \%$ of subjects aged $65-69$ were edentulous, and about $63.9 \%$ of subjects over 90 were also edentulous. Most of the edentulous individuals were women, but the difference was small [14]. A study investigating edentulism among residents of Valencia, Spain, showed that some $20.7 \%$ individuals aged $65-75$ were edentulous. This study revealed a statistically significant relationship between gender and edentulism - men were more likely to be edentulous [22]. Patel et al. noticed that women over 20 were more likely to have partial edentulism than men. The study was carried out on a South Indian population. In the case of the Polish population, there were more edentulous women than men [5].

The presented study shows that complete edentulism is most likely to happen in the maxilla (Class $\mathrm{V}$ according to Galasińska-Landsberger), while the highest percentage of edentulous space (Class IV according to GalasińskaLandsberger) was reported in the mandible, which translated into Class C2 according to Eichner (a denture without any support zone with one edentulous jaw). These findings were confirmed by Pels and Błaszczak, who examined the residents of nursing homes in the city of Lublin in south-eastern Poland, who most often used complete upper dentures and 
partial lower dentures [11]. Ayodeji Esan et al. conducted a study in Nigeria where they reported that most of their subjects needed complete dentures (partial dentures took second place) [13]. A study conducted in Bosnia revealed that more restorations were needed in the upper jaw, due to more frequent teeth losses in that area [21].

Abdel Rahman et al. used Kennedy Classes to describe teeth loss patterns. They noticed that Class III dental arch tendency decreased with age, while Classes I and Class II this tendency appeared more frequently [16]. These findings are consistent with the findings of the presented study - the number of teeth losses in the arch along with age, while there were fewer patients missing teeth in the mandible. Some authors investigating partial teeth losses concluded that Class III Kennedy losses (unilateral bounded partially edentulous patients) were the most frequent $[23,24,25]$. In the presented study it was noticed that mixed tooth losses were the most frequent, both in the maxilla and the mandible.

Numerous authors pointed to the relationship between education level and edentulism $[14,15,21,22,26]$. In the current study it was found that people who received primary education only were the most prone to edentulism. These findings are confirmed by an analysis of the 2 arches, most patients who came within Eichner Classes C2 and C3 had basic education only. A similar tendency was reported in a study investigating the population of Spain aged 65-74some $31.1 \%$ of edentulous individuals were those who had no schooling at all - illiterate people had the least teeth [22]. Panasiuk et al. conducted a study in the Lublin region of Poland and confirmed the relationship between education level and teeth losses - people who either declared incomplete primary or primary education had the highest average number of missing teeth. Furthermore, these numbers were twice as high than in the case of subjects who declared middle or post-secondary education (21.8 vs. 10.2) [19]. Similar findings were recorded among residents of the city of Wroclaw in south-western of Poland, aged 35-44 - subjects who had primary education only had less teeth than those with higher educational levels [18].

A study conducted in the United Kingdom revealed some inequalities in tooth loss related to one's education level the higher one's education level, the more teeth they had and the more likely they were to have more than 20 natural teeth [27]. Moreover, the following factors might contribute to teeth loss: low education, low income and staying single. Low education might cause teeth losses at an early age 20-35, and teeth loss risk caused by low education tends to decrease along with age [28]. A study conducted in Jordan revealed that individuals of the lowest educational level had the greatest demand for complete dentures [26]. In addition, a study conducted in Bulgaria revealed that subjects who had higher education (which lasted more than 12 years) were less likely to have missing teeth [17]. Bosnian authors concluded that the least educated people (primary education level only) re the most likely to become edentulous, unlike those with higher education. They conducted a study in the Serb Republic, the Serb entity within Bosnia and Herzegovina, which revealed that some $37 \%$ of edentulous subjects were people with primary education [21]. A study conducted in Italy revealed that some $52.4 \%$ of edentulous individuals were those with low education ( $0-3$ years), while some $3.3 \%$ were those with higher education (more than 8 years) [14]. A study conducted in Brazil revealed that edentulous people have the shortest mean education time, and individuals who had more than 20 natural teeth were reported to have the longest mean education time [7].

Ozkan et al. in their study conducted in Istanbul reported that people with both higher financial and educational status had better access to dental care. They point to the fact that there is huge demand for dental services among the members of that group [20]. The presented study did not analyze the relationship between financial status and dental health. However, various studies conducted in Europe, Asia and South America revealed that a poor financial status leads to teeth loss $[6,14,18]$, and that there is a close relationship between income levels and edentulism $[15,21]$; therefore, people reporting a low financial status are more likely to be edentulous [27]. This means that there is a higher demand for complete dentures among those a with low financial status, while those who are better off financially need partial dentures [26]. Also, people of a higher financial status are more likely to use prosthetic devices [8].

In the presented study, the Eichner Index was used to describe the patients, most of whom them were classified under $\mathrm{C}$ class. In cases where there was no prosthetic rehabilitation, teeth losses may lead to some morphological and functional changes in the masticatory system. Yoshino et al. noticed that subjects classified under Eichner Classes B4 and C3 had fewer than 9 permanent teeth, which decreases the biting force and chewing ability [29].

\section{CONCLUSIONS}

1. There were no gender differences when it came to the number of edentulous people.

2. Subjects with low education level were more likely to have fewer teeth than those with higher education.

3. Although though both age and education level affected the scope of teeth loss, gender had no direct influence on teeth losses. This was confirmed by 2 teeth loss classifications both topographical and occlusal-morphological.

\section{REFERENCES}

1. Kassebaum NJ, Bernabé E, Dahiya M, Bhandari B, Murray CJL, Marcenes W. Global Burden of Severe tooth loss: A Systematic Review and Meta-analysis. J Dent Res. 2014; 93(7): 20-28.

2. Williams J, Greene S, McNally S, Murray A, Quail A. Growing Up in Ireland National Longitudinal Study of Children. The Infants and their families. Infant cohort. Report 1. 2010.

3. Dahlgren G, Whitehead M. European strategies for tackling social inequities in health: Levelling up Part 2. WHO Regional Office for Europe 2006. Web site: www.euro.who.int.

4. Müller F, Naharro M, Carlsson GE. What are the prevalence and incidence of tooth loss in the adult and elderly population in Europe? Clin Oral Impl Res. 2007; 18(3): 2-14.

5. Jodkowska E. Stan uzębienia dorosłych mieszkańców Polski w latach 1998-2009. Przegl Epidemiol. 2010; 64: 571-576 (in Polish).

6. D’Souza MK, Aras M. Association between socio-demographic variables and partial edentulism in the Goan population: An epidemiological study in India. Indian J Dent Res. 2014; 25(4): 434-438.

7. Hugo FN, Hilgert JB, de Sousa Mda L, da Silva DD, Pucca GA Jr. Correlates of partial tooth loss and edentulism in the Brazilian elderly. Community Dent Oral Epidemiol. 2007; 35: 224-232.

8. Bhardwaj VK, Veeresha KL, Sharma KR. Dental prosthetic status, prosthetic needs in relation to socioeconomic status of the state government employees in Shimla city (Himachal Pradesh) - A cross sectional study. J Int Soc Prev Communit Dent. 2011; 1(2): 52-56. 
9. Majewski S. Podstawy protetyki w praktyce lekarskiej i technice dentystycznej. Wydawnictwo Stomatologiczne SZS-W. Kraków 2000 (in Polish).

10. Chhabra A, Chhabra N, Kabi D, Jain A. Understanding Dental Status and Treatment Need of Geriatric Patients: Oral Health Trends in an Indian Population. Oral Health Dent Manag. 2013; 12(4): 213-216.

11. Pels E, Błaszczak J. Ocena stanu uzębienia i protetycznych potrzeb u pensjonariuszy lubelskich domów pomocy społecznej. Gerontol Pol. 2012; 20(3): 95-101 (in Polish).

12. Basnyat KC S, Sapkota B, Shrestha S. Epidemiological Survey on Edentulousness in Elderly Nepalese Population. Kathmandu Univ Med J. 2014; 12(4): 259-263.

13. Esan TA, Olusile AO, Akeredolu PA, Esan AO. Socio-demographic factors and edentulism: the Nigerian experience. BMC Oral Health 2004; 4(3): 1-6.

14. Musacchio E, Perissinotto E, Binotto P, Sartori L, Silva-Netto F, Zambon S, Manzato E, Corti MC, Baggio G, Crepaldi G. Tooth loss in the elderly and its association with nutritional status, socio-economic and lifestyle factors. Acta Odontol Scand. 2007; 65: 78-86.

15. Peltzer K, Hewlett S, Yawson AE, Moynihan P, Preet R, Wu F, Guo G, Arokiasamy P, Snodgrass JJ, Chatterji S, Engelstad ME, Kowal P. Prevalence of Loss of All Teeth (Edentulism) and Associated Factors in Older Adults in China, Ghana, India, Mexico, Russia and South Africa. Int J Environ Res Public Health 2014; 11: 11308-11324.

16. Abdel-Rahman HK, Tahir CD, Saleh MM. Incidence of partial edentulism and its relation with age and gender. Zanco J Med Sci. 2013; 17(2): 463-470.

17. Damyanov ND, Witter DJ, Bronkhorst EM, Creugers NHJ. Dental Status and Associated Factors in a Dentate Adult Population in Bulgaria: A Cross-Sectional Survey. Int J Dent. 2012; 1-11.

18. Zawada E, Matuszewska A, Chrzęszczyk D, Konopka T. Utrata zębów u dorosłych mieszkańców Wrocławia. Dent Med Probl. 2012; 49(3): 391-398 (in Polish).

19. Panasiuk L, Kosiniak-Kamysz W, Horoch A, Paprzycki P, Karwat D. Tooth loss among adult rural and urban inhabitants of the Lublin Region. Ann Agric Environ Med. 2012; 20(3): 637-641.
20. Ozkan Y, Özcan M, Kulak Y, Kazazoglu E, Arica A. General health, dental status and perceived dental treatment needs of an elderly population in Istanbul. Gerodontology 2011; 28: 28-36.

21. Radović I, Davidović L, Krunić J, Stojanović N. Dental Status and Prosthetic Rehabilitation in Elderly Population in Relation to Socioeconomic Factors in Republika Srpska. Serbian Dent J. 2015; 62(1): 14-20.

22. Eustaquio-Raga MW, Montiel-Company JM, Almerich-Silla JM. Factors associated with edentulousness in an elderly population in Valencia (Spain). Gac Sanit. 2013; 27(2): 123-127.

23. Patel JY, Vohra MY, Hussain JM. Assessment of Partially Edentulous Patients Based on Kennedy's Classification and its Relation with Gender Predilection. Int J Scien Study. 2014; 2: 32-36.

24. Muneeb A, Moshin Khan B, Jamil B. Causes and pattern of partial edentulism/exodontia and its association with age and gender: semi rural population, Baqai dental college, Karachi, Pakistan. Int Dent J Stud Res. 2013; 1(3): 13-18.

25. Charyeva OO, Altynbekov KD, Nysanova BZ. Kennedy Classification and Treatment Options: A Study of Partially Edentulous Patients Being Treated in a Specialized Prosthetic Clinic J Prosth. 2012; 21: 177-180.

26. AL-Dwairi ZN. Need and Demand of Removable Dentures by Jordanian Adults and Relationship to Socioeconomic Factors. J Oral Hyg Health. 2013; 1(2): 1-5.

27. Bernabe E, Sheiham A. Tooth Loss in the United Kingdom - Trends in Social Inequalities: An Age-Period-and-Cohort Analysis. PLOS ONE. 2014; 9(8); 1-8.

28. Buchwald S, Kocher T, Biffar R, Harb A, Holtfreter B, Meisel P. Tooth loss and periodontitis by socio-economic status and inflammation in a longitudinal population-based study. J Clin Periodontol. 2013; 40: 203-21. DOI: $10.1111 /$ jcpe.12056.

29. Yoshino K, Kikukawa I, Yoda I, Watanabe H, Fukai K, Siughara N, et al. Relationship between Eichner Index and Number of present teeth. Bull Tokyo Dent Coll. 2012; 53(1): 37-40. 